\title{
Indexed Left Atrial Volume Is Superior to Left Atrial Diameter in Predicting Nonvalvular Atrial Fibrillation Recurrence after Successful Cardioversion: A Prospective Study
}

\author{
Procolo Marchese, M.D., ${ }^{*}$ Vincenzo Malavasi, M.D., ${ }^{*}$ Luca Rossi, M.D., ${ }^{*}$ Natalia Nikolskaya, M.D., ${ }^{*}$ \\ Grazia Delle Donne, M.D., ${ }^{*}$ Mirza Becirovic, M.D., ${ }^{*}$ Alessandra Colantoni, M.D., $\dagger$ Antonio Luciani, M.D., $\dagger$ \\ and Maria Grazia Modena, M.D.*
}

*Cardiology Unit and †Emergency Room, Modena University Hospital, Modena, Italy

Background: Although indexed left atrial volume (iLAV) is the most accurate measure of left atrial size, it has not been evaluated prospectively as predictor of recurrence of atrial fibrillation (AFib) after successful cardioversion (CV). Methods: We prospectively selected 76 patients (mean age $66.1 \pm 13.6$ years, $65.8 \%$ men) with AFib who underwent successful CV. Baseline clinical and echocardiographic characteristics were obtained before CV. LAV was measured using Simpson's method and indexed to body surface area. All patients were scheduled for follow-up visit at 1, 6, 12 months, and then annually. A 24-hour Holter ECG was performed within 6 months and each time the patients reported symptoms suggestive of arrhythmia. Results: The 52 patients (68.4\%) with AFib recurrence had larger iLAV $\left(35.5 \pm 8.9 \mathrm{~mL} / \mathrm{m}^{2}\right.$ vs $27.0 \pm 6.7 \mathrm{~mL} / \mathrm{m}^{2}, \mathrm{P}<0.001$ ). Anteroposterior LA diameter was not associated with AFib relapse (OR 1.08, 95\% Cl: 0.96-1.21, P = 0.09). Each unit increase in iLAV was associated with a 1.15-fold increased risk of recurrence (OR $1.15,95 \% \mathrm{Cl}: 1.06-1.25, \mathrm{P}<0.001)$. In a multivariable model, iLAV remained the only independent predictor of relapse (adjusted OR 1.14,95\% Cl: 1.02-1.28, P=0.02). The area under ROC curves, generated to compare LA diameter, and iLAV as predictors of AFib recurrence were 0.56 (SE 0.07) versus $0.78(S E 0.05)$, respectively $(P=0.003)$. Conclusion: This is the first prospective study to show that larger iLAV, as a more accurate measure of LA remodeling than anteroposterior diameter, is strongly and independently associated with a higher risk of AFib recurrence after CV. (Echocardiography 2012;29:276-284)

Key words: atrial fibrillation, cardioversion, left atrial remodeling, left atrial volume, recurrence, $\mathrm{CHA}_{2} \mathrm{DS}_{2} \mathrm{VASC}$

Despite the use of potent antiarrhythmic drugs (AAds), atrial fibrillation (AFib) relapse after cardioversion (CV) remains common, 1 leading to serial CV strategy. Among AFib recurrence predictors, ${ }^{2-4} \mathrm{M}$-mode anteroposterior left atrial diameter (AP-LAd), a unidimensional measure of left atrial (LA) size, was shown to be incremental to clinical risk factors. ${ }^{2,5,6}$ Although this measurement has been widely used in clinical practice and research, it inaccurately represents true LA size. 7,8 LA volume (LAV) determination is preferred because it allows a more accurate assessment of the asymmetric remodeling of the LA and it is a stronger predictor of cardiovascular outcomes than linear LA dimension. ${ }^{7}$ Nevertheless, its role in predicting recurrence of AFib after successful CV has been recently examined for the first

Conflict of interest: None declared.

Address for correspondence and reprint requests: Procolo Marchese, M.D., Largo del Pozzo, 71, 4100 Modena, Italy. Fax: +3959-4224498; E-mail: procolo.marchese@gmail.com time by our group in a retrospective study. ${ }^{9}$ Only one study has evaluated indexed left atrial volume (iLAV) as predictor of AFib, but the patients were maintained in sinus rhythm successfully for at least 1 month after conversion and then studied by transthoracic and transesophageal echocardiography. ${ }^{10}$ Therefore, the aims of the present work are to investigate in a prospective study whether iLAV predicts AFib recurrence after successful CV (pharmacological or direct-current) or it is incremental to clinical risk factors and AP-LAd.

\section{Methods:}

\section{Study Population:}

Given the pilot scope of the work, no formal sample size computation was performed. Nonetheless, before patient enrolment, we expected that including a total of 76 patients would have lead to $95 \%$ confidence intervals for AFib recurrence ranging between $50 \%$ and $72 \%$, in keeping with our previous retrospective work ${ }^{9}$ on this topic 
showing a point estimate of $61 \%$. We prospectively enrolled patients referred to emergency room for AFib, who underwent successful pharmacological or direct current CV between January 2008 and January 2009. Exclusion criteria were history of other atrial arrhythmias, congenital heart disease, moderate to severe valvular heart disease (including mitral valve prolapse), thyroid dysfunction, chronic obstructive pulmonary disease, acute (within 1 month before and at any time after $\mathrm{CV}$ ) or chronic inflammatory disease, any time cardiac surgery. Because surgical treatment may represent itself a trigger for AFib and because the mechanism underlying postoperative AFib are different from other types of AFib, ${ }^{11}$ we excluded patients who underwent all types of surgery within 3 months before and at any time after CV. We also excluded patients who received permanent pacemaker at any time before or after the date of the CV. We included patients who had successful restoration of sinus rhythm after CV and who had a transthoracic echocardiographic examination just before the CV. Each patient gave written informed consent and the study protocol was approved by our Institution Ethic Committee.

\section{Clinical Data:}

All clinical data on AFib risk factors were obtained at the time of the echocardiogram before CV and these included age, sex, hypertension, diabetes mellitus, hyperlipidemia, smoking, family history of cardiovascular disease, medical history of cardiovascular disease, duration of the AFib before CV, noting if it was of unknown duration, and number of previous episode(s) of AFib, noting if symptomatic for congestive heart failure. Hypertension, diabetes mellitus, hyperlipidemia, smoking, family history of cardiovascular disease, ${ }^{12}$ and $\mathrm{CHA}_{2} \mathrm{DS}_{2} \mathrm{VASc}^{13}$ were defined according to the latest guidelines. The Old $\mathrm{CHADS}_{2}$ [cardiac failure, hypertension, age, diabetes, stroke (doubled)] risk index is based on a point system in which two points are assigned for a history of stroke or TIA and one point each is assigned for age $>75$ years, a history of hypertension, diabetes, or recent cardiac failure; in patients with a $\mathrm{CHADS}_{2}$ score $\geq 2$, chronic oral anticoagulation therapy is recommended. The new $\mathrm{CHA}_{2} \mathrm{DS}_{2}$-VASc [congestive heart failure, hypertension, age $\geq 75$ (doubled), diabetes, stroke (doubled), vascular disease, age 65-74, and sex category (female)] extends the $\mathrm{CHADS}_{2}$ scheme by considering additional stroke risk factors allowing a better risk stratification. This scheme is based on a point system in which two points are assigned for a history of stroke or TIA, or age $\geq 75$; and one point each is assigned for age 65 74 years, a history of hypertension, diabetes, re- cent cardiac failure, vascular disease (myocardial infarction, complex aortic plaque, and PAD, including prior revascularization, amputation due to $P A D$, or angiographic evidence of $P A D$, etc.), and female sex. Chronic oral anticoagulation therapy is recommended for a score $\geq 2$.

The type of CV and the AAD used for pharmacological CV were recorded. All direct-current CVs were performed using biphasic defibrillator. Pharmacological therapy after CV, including AADs and the so-called "upstream therapy" for AFib recurrence prevention which encompasses ACE-inhibitors, Angiotensin II receptors blockers, statins, and polyunsaturated fatty acids, was also noted. Data collections and LA size assessment were performed in a blinded fashion.

\section{Echocardiographic Data:}

LAV was assessed off line with Simpson's method using apical four-chamber and apical twochamber views at ventricular end-systole ${ }^{8}$ and indexed to body surface area calculated using the DuBois and DuBois formula. ${ }^{14}$ Left atrial diameter was measured using two-dimensional (2D) anteroposterior linear dimension obtained from the parasternal long-axis view. Interoperator variability of our laboratory in assessing LA size has been previously published. ${ }^{15}$ For AP-LAd assessment, the mean difference \pm standard deviation between the measurements was $0.2 \pm 2.0$ $\mathrm{mm}$ and interclass correlation coefficient was 99.1\%; for LAV interobserver mean, difference was $0.2 \pm 5.5 \mathrm{~mL}$ and interclass correlation coefficient was $98.4 \%$, both indicating outstanding reliability. Patients with suboptimal images that precluded the assessment of LA volume were excluded. Left ventricular volume has been evaluated by the biplane method of disks (modified Simpson's rule) ${ }^{16}$ and then indexed to BSA. Left ventricular (LV) ejection fraction was visually estimated, a quick and widely used method that was documented to have an accuracy comparable to the other methods in assessing LV ejection fraction. ${ }^{17}$ Accordingly, we have compared the result of the EF measured with the volumes formula [(End systolic - End diastolic)/End systolic] with the visually estimated ones and the results are definitively analogous $60.8 \pm 5.2$ vs $62.1 \pm 6.1$. We did not used neither Teichholz nor Quinones methods of calculating EF from LV linear dimensions because they may result in inaccuracies as a result of the geometric assumptions required to convert a linear measurement to a three-dimensional volume. Left ventricular mass was calculated according to the current recommendations for chamber quantification, ${ }^{8}$ and indexed to body surface area (iLV-mass). Valvular regurgitation was assessed semiquantitatively by using color Doppler as absent, mild, moderate, or 
severe; alvular stenosis was assessed by Doppler analysis with the established methods. ${ }^{18,19}$ All other echocardiographic data were obtained according to the American Society of Echocardiography standards. ${ }^{8}$

\section{Outcomes Ascertainment:}

After CV, all patients were scheduled for follow-up visit, including 12-lead ECG at 1, 6, 12 months, and then annually. At least one 24-hour Holter ECG was performed within 6 months, and also each time the patients reported symptoms suggestive of arrhythmia.

To define AFib recurrence confirmation by ECG was required. No distinction was made between paroxysmal and persistent AFib relapse. Patients with a scheduled follow-up of at least 6 month were included.

\section{Statistical Analysis:}

Results are presented as mean \pm SD for continuous variables and as frequency (percentages) for categorical variables. Group comparisons were performed using the $t$-test or chi-square test, as appropriate. Logistic regression analysis was used to identify the univariate and multivariable predictors of AFib recurrence, the odds ratio (OR) and $95 \%$ confidence interval $(\mathrm{Cl})$ are shown. Pearson correlation was used to measure the association between two quantitative variables. Receiveroperator characteristic (ROC) curves were generated to compare M-mode AP-Lad, and iLAV as predictors of recurrence of AFib after CV. The areas under the ROC curves were compared using the method of DeLong et al. ${ }^{20}$ All tests are two sided and $P<0.05$ was considered to be significant. Statistical analysis was conducted using SPSS 15.0 and Medcalc 7.3.

\section{Results:}

\section{Baseline Characteristics and Clinical Predictors of AFib Recurrence:}

We evaluate 102 consecutive patients who underwent successful CV for AFib. After review of the medical records, 26 patients were not included because of the exclusion criteria. The remaining 76 patients (mean age $66.2 \pm 13.6$ years, $65.8 \%$ male) represent the study population.

Termination of the arrhythmia was achieved with pharmacological CV 40 (52.6\%) and with direct-current CV in 36 (47.4\%) patients. Pharmacological CV was obtained with $1 \mathrm{c}$ class AAds $34(85.0 \%)$ and amiodarone $6(15 \%)$.

For the overall cohort, 52 patients $(68.4 \%)$ developed AFib recurrence after a median time of 4.0 (minimum to maximum: 1.0-26.3) months. The remaining $24(31.6 \%)$ patients were free from AFib relapse for a median follow-up time of 32.9 (minimum to maximum: 25.8-36.8) months.

The baseline clinical characteristics of patients, stratified by AFib recurrence status at followup, are presented in Table I. Patients who subsequently developed AFib relapse were more likely to have hypertension, more previous AFib episodes, and higher $\mathrm{CHA}_{2} \mathrm{DS}_{2} \mathrm{VASc}$ score. Each point increase in $\mathrm{CHA}_{2} \mathrm{DS}_{2}$ VASc score was associated with a $94 \%$ increased risk of AFib recurrence (OR 1.94, Cl: 1.17-3.22, $\mathrm{P}=0.004$ ).

\section{Echocardiographic Predictors of AFib Recurrence:}

Patients with AFib recurrence had significantly greater iLAV than patients without AFib recurrence $(35.5 \pm 8.9$ vs $27.0 \pm 6.7, \mathrm{P}<0.001$, Table II). Furthermore, they had higher iLV-mass. Each $\mathrm{mL} / \mathrm{m}^{2}$ increase in iLAV was associated with a $15 \%$ increased risk of AFib relapse (OR 1.15, Cl: 1.06-1.25, $\mathrm{P}<0.001$, Table III). iLAV resulted also significantly correlated to $\mathrm{CHA}_{2} \mathrm{DS}_{2} \mathrm{VASC}$ score $\left(r=0.45, r^{2}=0.16, P<0.001 ;\right.$ Fig. 1$)$. Patients with moderate to severe LA enlargement (iLAV more than $33 \mathrm{~mL} / \mathrm{m}^{2}$ ) plus $\mathrm{CHA}_{2} \mathrm{DS}_{2}$ VASc score more than 2, resulted with a 9.42-fold increased risk of AFib recurrence (OR 9.42, Cl: 2.01-44.28, $\mathrm{P}=0.01$, Table III). AP-LAd was not significantly higher in patients with AFib relapse (Table II).

\section{Multivariable Predictors of AFib Recurrence:}

In a multivariable logistic regression model, iLAV remained the only predictor of AFib recurrence after adjusting for $\mathrm{CHA}_{2} \mathrm{DS}_{2}$ VASc score, hypertension, ACE-I therapy, number of previous AFib episodes, and iLV-mass (Table IV). Each $\mathrm{mL} / \mathrm{m}^{2}$ increase in iLAV was independently associated with a $13 \%$ increase in risk of AFib relapse (adjusted OR 1.14, Cl: 1.02-1.28, $\mathrm{P}=0.02$ ).

\section{Receiver-Operator Characteristic Curves Analysis:}

ROCs were generated to compare M-mode APLad, and iLAV as predictors of recurrence of AFib after CV (Fig. 2). The area under the curve was $0.78 \pm 0.05$ for iLAV versus $0.56 \pm 0.07$ for APLAd $(P<0.003)$. The best discriminating value of iLAV to predict AFib relapse was $31 \mathrm{~mL} / \mathrm{m}^{2}$, which had $71.2 \%$ sensitivity and $78.3 \%$ specificity. The cutoff value for severe iLAV enlargement $\left(40 \mathrm{~mL} / \mathrm{m}^{2}\right)$ corresponded to $26.9 \%$ sensitivity and $95.7 \%$ specificity. iLAV $42 \mathrm{~mL} / \mathrm{m}^{2}$ was $100 \%$ specific as predictor of AFib recurrence, although the sensitivity decreased to $17.3 \%$.

\section{Discussion:}

The present is the first prospective study to show that iLAV measured before CV is a significant and independent predictor of AFib recurrence. It is 
TABLE I

Characteristics of the Study Population at Baseline

\begin{tabular}{|c|c|c|c|}
\hline Variable & $\begin{array}{c}\text { NO AFib Recurrence } \\
\mathrm{n}=24(31.6 \%)\end{array}$ & $\begin{array}{l}\text { AFib Recurrence } \\
\mathrm{n}=52(68.4 \%)\end{array}$ & $P$ \\
\hline \multicolumn{4}{|l|}{ Clinical Characteristics } \\
\hline Sex (male) & $17(70.8)$ & $33(63.4)$ & 0.52 \\
\hline Age (years) & $63.3 \pm 18.0$ & $67.6 \pm 11.0$ & 0.20 \\
\hline $\mathrm{BMI}\left(\mathrm{kg} / \mathrm{m}^{2}\right)$ & $26.1 \pm 2.4$ & $27.2 \pm 4.6$ & 0.28 \\
\hline $\mathrm{BSA}\left(\mathrm{m}^{2}\right)$ & $1.9 \pm 0.2$ & $1.9 \pm 0.2$ & 0.93 \\
\hline Family history of CAD & $7(29.1)$ & $19(36.5)$ & 0.53 \\
\hline Hypertension & $13(54.2)$ & $41(78.8)$ & 0.03 \\
\hline Dyslipidemia & $8(33.3)$ & $25(48.1)$ & 0.23 \\
\hline Smoke & $2(8.3)$ & $5(9.6)$ & 0.86 \\
\hline Diabetes & $0(0.0)$ & $6(11.5)$ & 0.08 \\
\hline Known CAD & $1(4.2)$ & $8(15.4)$ & 0.16 \\
\hline Vascular disease & $0(0)$ & $0(0)$ & - \\
\hline Stroke & $0(0.0)$ & $3(5.8)$ & 0.23 \\
\hline $\mathrm{CHA}_{2} \mathrm{DS}_{2} \mathrm{VASC}$ & $1.5 \pm 0.9$ & $2.2 \pm 1.1$ & 0.04 \\
\hline AFib symptomatic for $\mathrm{CHF}$ & $0(0.0)$ & $1(1.9)$ & 0.49 \\
\hline AFib duration (days) & $12.4 \pm 3.2$ & $27.1 \pm 10.8$ & 0.20 \\
\hline Unknown AFib duration & $4(16.7)$ & $16(30.8)$ & 0.19 \\
\hline $\mathrm{N}^{\circ}$ of previous AFib episodes & $0.92 \pm 1.4$ & $2.40 \pm 4.4$ & 0.03 \\
\hline \multicolumn{4}{|c|}{$\begin{array}{l}\text { Antiarrhythmic drugs and "upstream" therapy after } \\
\text { cardioversion }\end{array}$} \\
\hline ACE-i & $2(8.3)$ & $17(32.7)$ & 0.02 \\
\hline ARBs & $4(16.7)$ & $17(32.7)$ & 0.15 \\
\hline Diuretics & $2(8.3)$ & $9(17.3)$ & 0.30 \\
\hline Dihydropyridine $\mathrm{Ca}^{2+}$ channel blockers & $1(4.2)$ & $6(11.5)$ & 0.30 \\
\hline Verapamil & $0(0.0)$ & $1(1.9)$ & 0.49 \\
\hline Diltiazem & $0(0.0)$ & $0(0.0)$ & - \\
\hline Digitalis & $1(4.2)$ & $0(0.0)$ & 0.14 \\
\hline Beta-blockers & $11(45.8)$ & $23(44.2)$ & 0.90 \\
\hline Ic/III class AAds & $9(37.5)$ & $29(55.7)$ & 0.14 \\
\hline Statins & $3(12.5)$ & $9(17.3)$ & 0.59 \\
\hline PUFA & $0(0.0)$ & $0(0.0)$ & - \\
\hline
\end{tabular}

Values in bold are statistically significant $\mathrm{P}<0.05$.

Data are presented as mean $\pm \mathrm{SD}$ or number (\%). AFib $=$ atrial fibrillation; $\mathrm{CAD}=$ coronary artery disease; $\mathrm{CHF}=$ congestive heart failure; CV = cardioversion; ACE-i = angiotensin converting enzyme inhibitors; ARBs = Angiotensin II receptor blockers; $\mathrm{AADs}=$ antiarrhythmic drugs; PUFA = polyunsaturated fatty acid; $\mathrm{OR}=$ odds ratio; $\mathrm{Cl}=$ confidence interval.

incremental to clinical risk factors and M-mode AP-LAd. Despite the emerging evidence that iLAV is a better predictor of a first episode of AFib than AP-LAd, ${ }^{21-23}$ the few studies evaluating the determinants of AFib recurrence after CV focused on AP-LAd. ${ }^{2,24,25}$ The role of iLAV in predicting relapse of AFib after successful CV has been recently examined for the first time by our group in a retrospective study. ${ }^{9}$ We demonstrated that larger iLAV before $C V$, as a more accurate measure of LA remodeling than LA diameter, was strongly and independently associated with higher risks of AFib recurrence. Only one study has evaluated iLAV as predictor of AFib, but the patients were maintained in sinus rhythm successfully for at least 1 month after conversion and then studied by transthoracic and transesophageal echocardiography. ${ }^{10}$ For optimal use of echocardiographic
LA size in AFib risk stratification, the method used for accurate quantification is pivotal. ${ }^{26}$ Our group previously demonstrated that the assessment of LA size by iLAV allows identification of patients with enlarged atria that would have been missed if classified by AP-LAd. ${ }^{15}$ Measurement of AP linear LA dimension by M-mode echocardiography is easy and rapid, but not reliably accurate, given that the $L A$ is not spherically shaped. The expansion of the LA in the AP dimension may be constrained by the thoracic cavity between the sternum and the spine. Predominant enlargement in the superior-inferior and mediallateral dimensions alters LA geometry such that the AP dimension may not be representative of LA size. Conversely, biplane iLAV by two-dimensional echocardiography provides a more accurate and reproducible estimation of LA size, when 


\section{TABLE II}

Baseline Echocardiographic Characteristics of the Study Population

\begin{tabular}{|c|c|c|c|}
\hline Variable & $\begin{array}{c}\text { No AFib } \\
\text { Recurrence } \\
\mathrm{n}=24 \\
(31.6 \%)\end{array}$ & $\begin{array}{c}\text { AFib } \\
\text { Recurrence } \\
\mathrm{n}=52 \\
(68.4 \%)\end{array}$ & P \\
\hline EF (\%) & $62.6 \pm 5.3$ & $61.9 \pm 7.5$ & 0.67 \\
\hline LV-Dd (mm) & $45.3 \pm 6.0$ & $46.2 \pm 6.1$ & 0.61 \\
\hline LV-Sd (mm) & $18.1 \pm 2.7$ & $19.4 \pm 4.9$ & 0.30 \\
\hline AP-LAD $(\mathrm{mm})$ & $36.3 \pm 3.2$ & $38.1 \pm 5.6$ & 0.09 \\
\hline $\operatorname{iLAV}\left(\mathrm{mL} / \mathrm{m}^{2}\right)$ & $27.0 \pm 6.7$ & $35.5 \pm 8.9$ & $<\mathbf{0 . 0 0 1}$ \\
\hline iLV-mass $\left(\mathrm{g} / \mathrm{m}^{2}\right)$ & $101.0 \pm 26.4$ & $120.7 \pm 31.3$ & 0.02 \\
\hline $\begin{array}{l}\text { iLV-volume } \\
\left(\mathrm{mL} / \mathrm{m}^{2}\right)\end{array}$ & $56.13 \pm 21.3$ & $53.6 \pm 17.2$ & 0.68 \\
\hline $\begin{array}{l}\text { Mitral } \\
\quad \text { regurgitation }\left(^{\circ}\right)\end{array}$ & $8(33.3)$ & $21(40.4)$ & 0.92 \\
\hline $\begin{array}{l}\text { Aortic } \\
\quad \text { regurgitation }\left(^{\circ}\right)\end{array}$ & $4(16.7)$ & $19(36.5)$ & 0.19 \\
\hline $\begin{array}{l}\text { Tricuspid } \\
\quad \text { regurgitation }\left(^{\circ}\right)\end{array}$ & $10(41.7)$ & $19(36.5)$ & 0.26 \\
\hline $\begin{array}{l}\mathrm{iLAV}>33 \mathrm{~mL} / \mathrm{m}^{2} \\
\quad+\mathrm{CHA}_{2} \mathrm{DS}_{2} \text { VASc }\end{array}$ & $2^{2(8.3)}$ & $24(46.1)$ & 0.01 \\
\hline
\end{tabular}

Values in bold are statistically significant $\mathrm{P}<0.05$.

Data are presented as mean \pm SD or number (\%). AFib = atrial fibrillation; $E F=$ ejection fraction; $L V-D d=$ left ventricular diastolic diameter; AP-LAd = M-mode anteroposterior left atrial diameter; $i \mathrm{LAV}=$ indexed left atrial volume; $\mathrm{iLV}=$ indexed left ventricular.

compared with reference standards such as magnetic resonance imaging ${ }^{27}$ and three-dimensional echocardiography. ${ }^{28}$ Accordingly, the ASE/ESC have recommended quantification of LA size by biplane volumetric 2D echocardiography using either the Simpson method or the area-length method which are comparable in accuracy and reproducibility. ${ }^{8}$

Despite this growing evidence, the latest guidelines for AFib management ${ }^{13}$ have included LA size assessment just in terms of $\mathrm{M}$-mode AP dimension. The present study, confirming the results of our retrospective one, supports the findings that iLAV is superior to AP-LAd as predictor of AFib recurrence.

\section{LA Remodeling as Predictor of AFib \\ Recurrence:}

LA remodeling refers to a time-dependent adaptive regulation of cardiac myocytes in order to maintain homeostasis against external "stressors." 29 The type, extent, and reversibility of atrial remodeling depend on the strength and the duration of exposure to the stressors. The most common stressors of atrial myocytes include volume/pressure overload and tachycardia. They are not mutually exclusive and usually may coexist at various times in the same patient. Increased volume/pressure overload leads to chamber dilatation and stretch of the atrial myocardium providing the substrate for AFib to be sustained. ${ }^{29}$ Tachycardia-induced LA remodeling is mostly reversible, even if a prolonged high rates of cell depolarization makes restoring and maintaining sinus rhythm less likely. ${ }^{30,31}$

The structural changes of the LA reflect an average effect of left ventricle filling pressures over time due to reduced left ventricle compliance, rather than an instantaneous measurement at the time of study. ${ }^{26}$ This is common in various conditions such as hypertension, diabetes, coronary artery disease, and chronic heart failure, ${ }^{32}$ supporting the hypothesis that AFib may be a symptom of an underlying left ventricle disease. According to these findings, ${ }^{29}$ present study shows that $\mathrm{CHA}_{2} \mathrm{DS}_{2}$ VASc score, hypertension, and iLV-mass are associated with higher probability of AFib relapse. Present work is the first to evaluate the relationship between the $\mathrm{CHA}_{2} \mathrm{DS}_{2}$ VASc score, iLAV, and AFib recurrence after $\mathrm{CV}$. $\mathrm{CHA}_{2} \mathrm{DS}_{2}$ VASc is the new score used to predict the risk of stroke in AFib patients. ${ }^{13}$ We showed that it is associated with higher risk of AFib recurrence, accordingly with the assumption that the more the AFib burden the more the risk of stroke. ${ }^{33}$ Previous studies have demonstrated the relationship between LA diameter, $\mathrm{CHADS}_{2}$, and risk of stroke. ${ }^{34,35}$ In our study, $\mathrm{CHA}_{2} \mathrm{DS}_{2}$ VASc score resulted also significantly correlated to iLAV (Fig. 1). Probably the reason is because the $\mathrm{CHA}_{2} \mathrm{DS}_{2}$ VASc score includes the above-mentioned "stressors" leading to LA remodeling. However, in the multivariable model, iLAV remained the only significant predictor of AFib recurrence, resulting superior to clinical risk factors included in $\mathrm{CHA}_{2} \mathrm{DS}_{2}$ VASc score, and AADs, maybe because LA remodeling represents the final and macroscopic result of the sum of each single clinical predictor. Otherwise, it is interesting to note that patients with $\mathrm{CHA}_{2} \mathrm{DS}_{2} \mathrm{VASC}$ score more than two points and moderate to severe LA enlargement (iLAV more than $33 \mathrm{~mL} / \mathrm{m}^{2}$ ) had a 9.42 -fold increased risk of AFib relapse.

It would be hard and intriguing to establish which one is the point of no return. The risk of AFib recurrence increases significantly for iLAV above $31.0 \mathrm{~mL} / \mathrm{m}^{2}$. This is quite the same value reported by previous studies that have evaluated the role of iLAV as predictor of major cardiovascular events and mortality ${ }^{26}$ and by our retrospective experience. ${ }^{9}$ It is likely that some grade of irreversibility begins in the range of moderate iLAV enlargement. As expected, the larger the iLAV, the more is the risk of AFib relapse, probably because of the higher grade of LA fibrosis. 
TABLE III

Univariate Model

\begin{tabular}{|c|c|c|c|}
\hline Variable & $P$ & OR & $\mathrm{Cl}$ \\
\hline \multicolumn{4}{|l|}{ Clinical Characteristics } \\
\hline Sex (male) & 0.52 & 0.71 & $0.25-2.03$ \\
\hline Age (years) & 0.20 & 1.02 & $0.99-1.05$ \\
\hline $\operatorname{BMl}\left(\mathrm{kg} / \mathrm{m}^{2}\right)$ & 0.28 & 1.08 & $0.94-1.23$ \\
\hline $\operatorname{BSA}\left(\mathrm{m}^{2}\right)$ & 0.93 & 1.11 & $0.08-14.90$ \\
\hline Family history of CAD & 0.53 & 1.40 & $0.49-3.98$ \\
\hline Hypertension & 0.03 & 3.15 & $1.11-8.95$ \\
\hline Dyslipidemia & 0.23 & 1.85 & $0.67-5.07$ \\
\hline Smoke & 0.86 & 1.17 & $0.21-6.51$ \\
\hline Diabetes & 0.08 & 0.66 & $0.55-0.78$ \\
\hline Known CAD & 0.16 & 4.18 & $0.49-35.51$ \\
\hline Stroke & 0.23 & 0.67 & $0.57-0.79$ \\
\hline $\mathrm{CHA}_{2} \mathrm{DS}_{2} \mathrm{VASC}$ & 0.04 & 1.94 & $1.17-3.22$ \\
\hline Afib symptomatic for CHF & 0.49 & 0.68 & $0.58-0.79$ \\
\hline Afib duration (days) & 0.20 & 1.01 & $0.98-1.03$ \\
\hline Unknown Afib duration & 0.19 & 2.22 & $0.65-7.56$ \\
\hline $\mathrm{N}^{\circ}$ of previous Afib episodes & 0.03 & 1.20 & $1.01-1.54$ \\
\hline \multicolumn{4}{|l|}{ Echocardiography Data } \\
\hline $\mathrm{EF}(\%)$ & 0.67 & 0.98 & $0.91-1.07$ \\
\hline LV-Dd (mm) & 0.61 & 1.02 & $0.93-1.13$ \\
\hline LV-Sd (mm) & 0.30 & 1.09 & $0.92-1.30$ \\
\hline $\mathrm{AP}-\mathrm{LAD}(\mathrm{mm})$ & 0.09 & 1.08 & $0.96-1.21$ \\
\hline $\operatorname{iLAV}\left(\mathrm{mL} / \mathrm{m}^{2}\right)$ & $<0.001$ & 1.15 & $1.06-1.25$ \\
\hline iLV-mass $\left(\mathrm{g} / \mathrm{m}^{2}\right)$ & 0.02 & 1.03 & $1.002-1.05$ \\
\hline iLV-volume $\left(\mathrm{mL} / \mathrm{m}^{2}\right)$ & 0.68 & 1.00 & 0.96 .1 .03 \\
\hline Mitral regurgitation $\left({ }^{\circ}\right)$ & 0.92 & 0.94 & $0.31-2.88$ \\
\hline Aortic regurgitation $\left({ }^{\circ}\right)$ & 0.19 & 2.29 & $0.64-8.10$ \\
\hline Tricuspid regurgitation $\left({ }^{\circ}\right)$ & 0.26 & 0.49 & $0.16-1.52$ \\
\hline $\mathrm{iLAV}>33 \mathrm{~mL} / \mathrm{m}^{2}+\mathrm{CHA}_{2} \mathrm{DS}_{2} \mathrm{VASC}>2$ & 0.01 & 9.42 & $2.01-44.28$ \\
\hline \multicolumn{4}{|c|}{ Antiarrhythmic Drugs and "Upstream" Therapy after Cardioversion } \\
\hline ACE-i & 0.02 & 5.34 & $1.12-25.40$ \\
\hline ARBs & 0.15 & 2.43 & $0.71-8.22$ \\
\hline Diuretics & 0.30 & 2.30 & $0.46-11.59$ \\
\hline Dihydropyridine $\mathrm{Ca}^{2+}$ channel blockers & 0.30 & 3.00 & $0.34-26.42$ \\
\hline Verapamil & 0.49 & 0.68 & $0.58-0.79$ \\
\hline Digitalis & 0.14 & 0.31 & $0.22-0.43$ \\
\hline Beta-blockers & 0.90 & 0.93 & $0.35-2.47$ \\
\hline Ic/III class AAds & 0.14 & 2.10 & $0.78-5.66$ \\
\hline Statins & 0.59 & 1.46 & $0.36-5.98$ \\
\hline
\end{tabular}

Values in bold are statistically significant $\mathrm{P}<0.05$.

$\mathrm{AFib}=$ atrial fibrillation; $\mathrm{CAD}=$ coronary artery disease; $\mathrm{CHF}=$ congestive heart failure; $\mathrm{CV}=$ cardioversion; $\mathrm{LV}$-Dd = left ventricular diastolic diameter; AP-LAd = M-mode anteroposterior left atrial diameter; iLAV = indexed left atrial volume; iLV = indexed left ventricular; $\mathrm{ACE}-\mathrm{i}=$ angiotensin converting enzyme inhibitors; $\mathrm{ARBs}=$ Angiotensin II receptor blockers; $\mathrm{AADs}=$ antiarrhythmic drugs; $\mathrm{PUFA}=$ polyunsaturated fatty acid; $\mathrm{OR}=$ odds ratio; $\mathrm{Cl}=$ confidence interval.

\section{Strengths and Limitations:}

The major strength of the present study is that it is the first to test prospectively the predictive role of LAV in the post CV setting. Furthermore, all echocardiographic studies were performed before CV according to the American Society/European Society of Echocardiography standards and interoperator variability of our laboratory in assessing LAV has been previously published. ${ }^{15}$ LAV was indexed to body surface area. Physicians measuring iLAV data off line were blinded to the clinical data and outcomes of the patients.

The clinical follow-up was scheduled at 1, 6, and 12 months and then annually; at least one 24-hour Holter ECG was performed within 6 months, and also each time the patients reported symptoms suggestive an arrhythmia. Furthermore, we excluded patients with a followup of less than 6 months in order to guarantee a sufficiently long follow-up. Only clinically documented AFib was considered, thus we cannot 


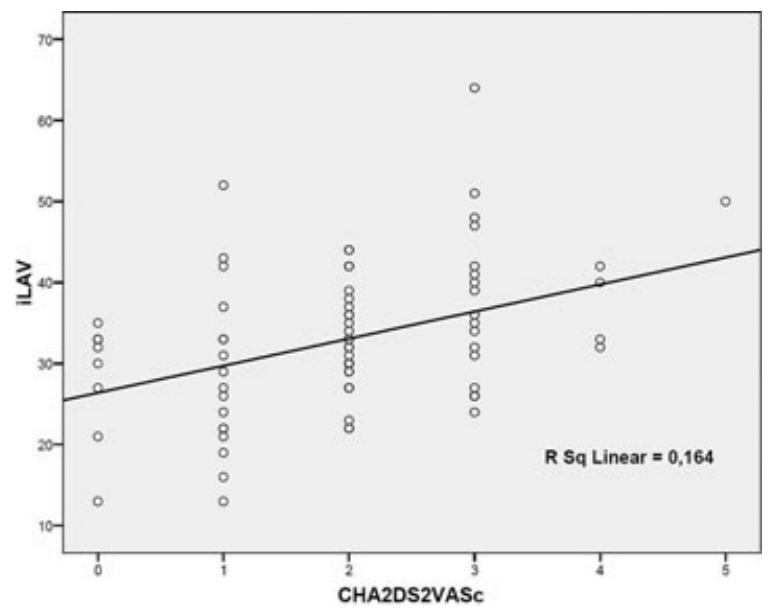

Figure 1. Pearson correlation between ILAV and $\mathrm{CHA}_{2} \mathrm{DS}_{2}$ VASc score.

exclude that some patients had asymptomatic AFib recurrence.

Mean EF is normal. If a more representative group of patients were enrolled it is hard to imagine that EF would not be a predictor. Nevertheless, it would be reasonable to assume that patients with lower EF would have also a proportionate iLAV enlargement. This is consistent with our previous published paper on a larger retrospective cohort which showed that EF was a predictor of AFib relapse at univariate analysis, but not in the multivariable model. ${ }^{9}$

This is the first study to evaluate the relationship between iLAV, $\mathrm{CHA}_{2} \mathrm{DS}_{2}$ VASc score, and $A F i b$ relapse after $C V$, showing intriguing results.

Giving the number of the cohort, these topics should be investigated in a larger prospective study, even if this work confirms the results of our retrospective one based on a larger population.

\section{TABLE IV}

Multivariable Predictors of AFib Recurrence

\begin{tabular}{lccl}
\hline Variable & $P$ & OR & \multicolumn{1}{c}{$\mathrm{Cl}$} \\
\hline $\mathrm{CHAD}_{2} \mathrm{~S}_{2}$ VASc & 0.51 & 0.96 & $0.16-5.74$ \\
Hypertension & 0.65 & 0.96 & $0.16-5.73$ \\
ACE-i & 0.32 & 2.74 & $0.39-19.94$ \\
$\mathrm{~N}^{\circ}$ of previous AFib Episodes & 0.25 & 1.21 & $0.87-1.68$ \\
iLVmass $\left(\mathrm{g} / \mathrm{m}^{2}\right)$ & 0.92 & 1.00 & $0.97-1.03$ \\
iLAV $\left(\mathrm{mL} / \mathrm{m}^{2}\right)$ & $\mathbf{0 . 0 2}$ & $\mathbf{1 . 1 4}$ & $\mathbf{1 . 0 2 - 1 . 2 8}$ \\
\hline
\end{tabular}

Values in bold are statistically significant $P<0.05$.

ACE- $\mathrm{i}=$ indicates angiotensin converting enzyme inhibitors; $\mathrm{iLAV}=$ indexed left atrial volume; iLV = indexed left ventricular; $\mathrm{OR}=$ odds ratio; $\mathrm{Cl}=$ confidence interval.

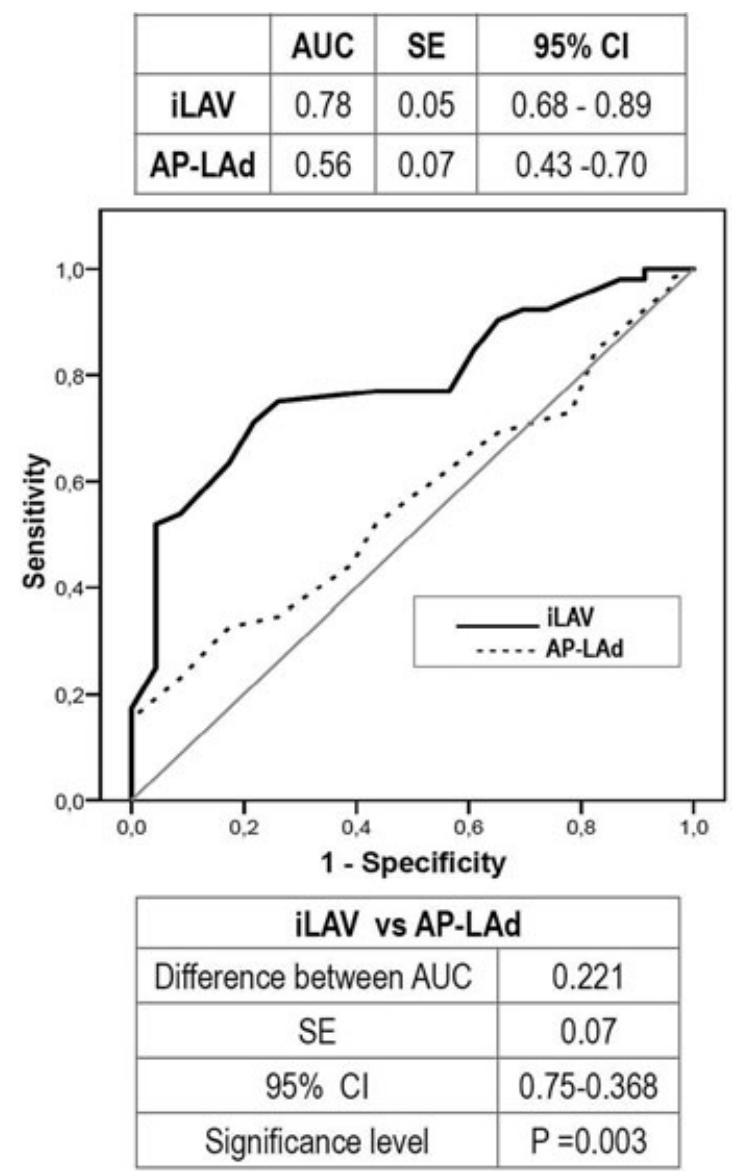

Figure 2. Receiver-operator characteristic curves generated to compare M-mode AP-LAd and iLAV as predictors of recurrence of AFib after cardioversion. AFib = atrial fibrillation; $\mathrm{AUC}=$ area under the curve; $\mathrm{SE}=$ standard error; $\mathrm{Cl}=$ confidence interval; AP-LAd = M-mode anteroposterior left atrial diameter; $\mathrm{iLAV}=$ indexed left atrial volume.

\section{Conclusions:}

The present prospective study demonstrates that iLAV is a significant and independent predictor of AFib recurrence after successful CV, confirming the results of our retrospective one. It is superior to M-mode AP-LAd because it allows a more accurate assessment of the asymmetric remodeling of the LA. Furthermore, iLAV is incremental to clinical risk factors, and medical therapy in predicting AFib relapse, likely because LA remodeling represents the final and macroscopic result of the sum of each single predictor. Although latest guidelines for AFib management ${ }^{13}$ mention LA size assessment just in terms of M-mode AP dimension, the present study encourages the use of iLAV as a valuable tool for the clinician managing patients with AFib. Larger prospective studies are needed to establish iLAV utility in AFib management. 


\section{References}

1. Bertaglia E, D'Este D, Zerbo F, et al: Success of serial external electrical cardioversion of persistent atrial fibrillation in maintaining sinus rhythm; a randomized study. Eur Heart J 2002;23:1522-1528.

2. Olshansky B, Heller EN, Mitchell LB, et al: Are transthoracic echocardiographic parameters associated with atrial fibrillation recurrence or stroke? Results from the atrial fibrillation follow-up investigation of rhythm management (AFFIRM) study. J Am Coll Cardiol 2005;45:2026-2033.

3. Kosior DA, Szulc M, Opolski G, et al: Long-term sinus rhythm maintenance after cardioversion of persistent atrial fibrillation: Is the treatment's success predictable? Heart Vessels 2006;21:375-381.

4. Raitt MH, Volgman AS, Zoble RG, et al: Prediction of the recurrence of atrial fibrillation after cardioversion in the atrial fibrillation follow-up investigation of rhythm management (AFFIRM) study. Am Heart J 2006;151:390-396.

5. Parkash R, Green MS, Kerr CR, et al: The association of left atrial size and occurrence of atrial fibrillation: A prospective cohort study from the Canadian Registry of Atrial Fibrillation. Am Heart J 2004;148:649-654.

6. Kerr CR, Humphries KH, Talajic M, et al: Progression to chronic atrial fibrillation after the initial diagnosis of paroxysmal atrial fibrillation: Results from the Canadian Registry of Atrial Fibrillation. Am Heart / 2005;149:489-496.

7. Tsang TS, Abhayaratna WP, Barnes ME, et al: Prediction of cardiovascular outcomes with left atrial size: Is volume superior to area or diameter? I Am Coll Cardiol 2006;47:1018-1023.

8. Lang RM, Bierig M, Devereux RB, et al: Recommendations for chamber quantification. Eur J Echocardiogr 2006;7:79108.

9. Marchese P, Bursi F, Delle Donne G, et al: Indexed left atrial volume predicts the recurrence of non-valvular atrial fibrillation after successful cardioversion. Eur J Echocardiogr 2011;12:214-221.

10. Wang YC, Lin LC, Lin MS, et al: Identification of good responders to rhythm control of paroxysmal and persistent atrial fibrillation by transthoracic and transesophageal echocardiography. Cardiology 2005;104:202-209.

11. Osranek M, Fatema K, Qaddoura F, et al: Left atrial volume predicts the risk of atrial fibrillation after cardiac surgery: A prospective study. I Am Coll Cardiol 2006;48:779-786.

12. Graham I, Atar D, Borch-Johnsen K, et al: European guidelines on cardiovascular disease prevention in clinical practice: Full text. Fourth Joint Task Force of the European Society of Cardiology and other societies on cardiovascular disease prevention in clinical practice (constituted by representatives of nine societies and by invited experts). Eur J Cardiovasc Prev Rehabil 2007;14(Suppl 2):S1-S113.

13. Camm AJ, Kirchhof P, Lip GY, et al: Guidelines for the management of atrial fibrillation: The Task Force for the Management of Atrial Fibrillation of the European Society of Cardiology (ESC). Eur Heart J 2010;31:2369-2429.

14. Du Bois D, Du Bois EF: A formula to estimate the approximate surface area if height and weight be known. 1916. Nutrition 1989;5:303-311; discussion 12-13.

15. Barbieri A, Bursi F, Zanasi V, et al: Left atrium reclassified: Application of the American Society of Echocardiography/European Society of Cardiology cutoffs to unselected outpatients referred to the echocardiography laboratory. J Am Soc Echocardiogr 2008;21:433-438.

16. Lang RM, Bierig M, Devereux RB, et al: Recommendations for chamber quantification: A report from the American Society of Echocardiography's Guidelines and Standards Committee and the Chamber Quantification Writing Group, developed in conjunction with the European Association of Echocardiography, a branch of the European Society of Cardiology. I Am Soc Echocardiogr 2005;18:1440-1463.
17. Amico AF, Lichtenberg GS, Reisner SA, et al: Superiority of visual versus computerized echocardiographic estimation of radionuclide left ventricular ejection fraction. Am Heart / 1989;118:1259-1265.

18. Bonow RO, Carabello BA, Chatterjee K, et al: Focused update incorporated into the ACC/AHA 2006 guidelines for the management of patients with valvular heart disease: A report of the American College of Cardiology/American Heart Association Task Force on Practice Guidelines (Writing Committee to Revise the 1998 Guidelines for the Management of Patients With Valvular Heart Disease): Endorsed by the Society of Cardiovascular Anesthesiologists, Society for Cardiovascular Angiography and Interventions, and Society of Thoracic Surgeons. Circulation 2008;118:e523-e661.

19. Vahanian A, Baumgartner H, Bax J, et al: Guidelines on the management of valvular heart disease: The Task Force on the Management of Valvular Heart Disease of the European Society of Cardiology. Eur Heart J 2007;28:230-268.

20. DeLong ER, DeLong DM, Clarke-Pearson DL: Comparing the areas under two or more correlated receiver operating characteristic curves: A nonparametric approach. Biometrics 1988;44:837-845.

21. Tsang TS, Barnes ME, Bailey KR, et al: Left atrial volume: important risk marker of incident atrial fibrillation in 1655 older men and women. Mayo Clin Proc 2001;76:467-475.

22. Tsang TS, Barnes ME, Gersh BJ, et al: Left atrial volume as a morphophysiologic expression of left ventricular diastolic dysfunction and relation to cardiovascular risk burden. $\mathrm{Am}$ J Cardiol 2002;90:1284-1289.

23. Tsang TS, Gersh BJ, Appleton CP, et al: Left ventricular diastolic dysfunction as a predictor of the first diagnosed nonvalvular atrial fibrillation in 840 elderly men and women. I Am Coll Cardiol 2002;40:16361644.

24. Vaziri SM, Larson MG, Benjamin EJ, et al: Echocardiographic predictors of nonrheumatic atrial fibrillation. The Framingham Heart Study. Circulation 1994;89:724-730.

25. Psaty BM, Manolio TA, Kuller LH, et al: Incidence of and risk factors for atrial fibrillation in older adults. Circulation 1997;96:2455-2461.

26. Abhayaratna WP, Seward JB, Appleton CP, et al: Left atrial size: Physiologic determinants and clinical applications. I Am Coll Cardiol 2006;47:2357-2363.

27. Rodevan $\mathrm{O}$, Bjornerheim $\mathrm{R}$, Ljosland $\mathrm{M}$, et al: Left atrial volumes assessed by three- and two-dimensional echocardiography compared to MRI estimates. Int / Card Imaging 1999;15:397-410.

28. Maddukuri PV, Vieira ML, DeCastro $S$, et al: What is the best approach for the assessment of left atrial size? Comparison of various unidimensional and twodimensional parameters with three-dimensional echocardiographically determined left atrial volume. J Am Soc Echocardiogr 2006;19:1026-1032.

29. Casaclang-Verzosa G, Gersh BJ, Tsang TS: Structural and functional remodeling of the left atrium: Clinical and therapeutic implications for atrial fibrillation. / Am Coll Cardiol 2008;51:1-11.

30. Ricard P, Levy S, Trigano J, et al: Prospective assessment of the minimum energy needed for external electrical cardioversion of atrial fibrillation. Am / Cardiol 1997;79:815816.

31. Wijffels MC, Kirchhof C], Dorland R, et al: Atrial fibrillation begets atrial fibrillation. A study in awake chronically instrumented goats. Circulation 1995;92:1954-1968.

32. Lester SJ, Tajik AJ, Nishimura RA, et al: Unlocking the mysteries of diastolic function: Deciphering the Rosetta Stone 10 years later. J Am Coll Cardiol 2008;51:679-689.

33. Connolly SJ, Crijns HJ, Torp-Pedersen C, et al: Analysis of stroke in ATHENA: A placebo-controlled, double-blind, parallel-arm trial to assess the efficacy of dronedarone $400 \mathrm{mg}$ BID for the prevention of cardiovascular 
hospitalization or death from any cause in patients with atrial fibrillation/atrial flutter. Circulation 2009;120:11741180.

34. Kleemann $T$, Becker $T$, Strauss $M$, et al: Prevalence and clinical impact of left atrial thrombus and dense spontaneous echo contrast in patients with atrial fibrillation and low CHADS2 score. Eur J Echocardiogr 2009;10:383388.

35. McBane RD, Hodge DO, Wysokinski WE: Clinical and echocardiographic measures governing thromboembolism destination in atrial fibrillation. Thromb Haemost 2008;99:951-955. 